\title{
GLOBALIZATION, CULTURE, CONSUMER DISPOSITIONS, AND CONSUMPTION: THE CASE OF IRAN
}

\author{
Mark Cleveland, University of Western Ontario, Canada \\ Michel Laroche, Concordia University, Canada \\ Parastoo Naghavi, Concordia University, Canada \\ Mohammad Ali Shafia, Iran University of Science and Technology, Iran
}

\begin{abstract}
Culture is recognized as the most fundamental shaper of consumer behavior. Global forces inexorably penetrate the economic, political, and social realms. It is critical to understand the impact of globalization on the cultural makeup and subsequent behaviors of consumers worldwide. In the wake of globalization, and to attract and serve customers around the world, marketers need to understand where and when cultures and consumers are homogenizing, and the contexts under which diversity is likely to persist or even intensify.
\end{abstract}

Identity is the locus of cultural effects; therefore, this research focuses on the critical roles of local culture ethnic identity (EID), alongside exposure to and acceptance of cultural forces that transcend borders (acculturation to global consumer culture: AGCC), in shaping the dispositions (consumer ethnocentrism, cosmopolitanism and materialism: CET, COS, MAT) and behaviors (spanning 7 product categories) of consumers living in Iran - a research context well-suited for examining the competing pulls of global and local cultural forces. Iran ranks among the largest 20 national economies in the world. Belying the country's economic clout, very little is known about the modern Iranian consumer; judging by the paucity of published marketing research on Iran (due mainly to the difficulty of conducting research in that country). The country's rich cultural heritage, the tumultuous social changes experienced by its people, its geopolitical status and middle-income consumer ranking together make Iran a fascinating and most worthy locale for the study of globalization, culture, consumer dispositions, and consumption.

Existing scale measures (Cleveland and Laroche, 2007; Richins, 2004; Cleveland and Chang, 2009; Shimp and Sharma, 1987) were translated from English into Farsi, and then backtranslated to assess equivalency. The survey also contained demographic measures, and 47 distinct consumer behaviors, corresponding to the consumption of the following broad product-market categories: local (Iranian) foods (10 items), global foods (9 items), global apparel (4 items), appliances and durables (5 items), consumer electronics and associated technological uses (6 and 7 items, respectively), as well as luxuries (6 items); all of which were subjected to translation/back-translation. The sample ( $\mathrm{n}=298$ usable surveys) consisted of current and former university students at a major urban university in Tehran. SPSS and AMOS were employed to analyze the data, which consisted of exploratory and confirmatory factor analyses, cluster and reliability analyses, bivariate and partial correlations, as well as structural equations modelling.

Four consumer clusters were delineated on the basis of adherence to local culture and absorption of global consumer culture: biculturals, locals, marginals, and locals. The inverse link between AGCC and EID is suggestive of both assimilation and cultural resistance. Both cultural constructs were positively related to the dispositions of COS and MAT, whereas only EID was significantly antecedent to CET. The low mean score of AGCC-relative to EID and COS, of which a strongly positively interrelationship existed - suggests that while exposure to foreign influences (e.g., media, marketing) remains subdued, Iranians nonetheless are open to different cultures and embrace divergent cultural encounters, while proudly promoting an Iranian identity. Thus, by and large, Iranians have a bicultural identity; one part incorporating an international outlook combined with another part strongly embedded in local traditions. The linkages between the cultural and dispositional constructs to consumer behavior, varied substantially across the 47 consumption cases, in terms of direction, magnitude, and explanatory power.

From a practical perspective, the findings identify which products and categories are possible candidates for standardized marketing strategies (e.g., global apparel), versus local strategies emphasizing ethnic traditions (e.g, some local foods, certain appliances), versus glocalization strategies combining local and global elements (e.g., modern electronics, technology, and certain luxury products). Methodological contributions of this research includes the validation of construct measures in the Farsi language, and the application of consumer theory in Iran - an important emerging economy that has largely been overlooked in marketing research.

References available upon request. 